\title{
Educational innovation in basic and advanced cardiopulmonary resuscitation in pediatrics and neonatology in a realistic context
}

García-Molina, Pablo ${ }^{a}$; Blasco-Igual, Jose María ${ }^{b}$ Balaguer-López, Evelyn ${ }^{a}$; Tortajada Alejandro-Lohaces ${ }^{a}$; Sanchis-Sánchez, Enrique ${ }^{b}$; Georgieva, Sylvia ${ }^{c}$ and Sánchez-Lorente, María Montserrat ${ }^{\mathrm{d}}$

${ }^{a}$ Department of Nursing, University of Valencia, Spain. ${ }^{b}$ Department of Physiotherapy, University of Valencia, Spain. ' Department of Methodology and Behavioral Sciences, University of Valencia, Spain and ${ }^{\mathrm{d}}$ Conselleria de Sanitat, Generalitat Valenciana, Spain.

\begin{abstract}
Introduction: The university professor has to transmit the technical and cognitive skills on Cardiopulmonary Resuscitation (CPR) in Pediatrics with the most effective method.

Methodology: 17 practical classes of Cardiopulmonary Resuscitation of 2 hours for 225 students the 2nd year of the Pediatric Nursing course at the University of Valencia were taught. Each class consisted of 3 clinical cases in which 15 students and 3 monitors participated. The knowledge of the students was evaluated with test-retest of 11 questions and the satisfaction after the simulation (questionnaire of 20 questions).

Results: The satisfaction mean of the students was of 8,62 on 10 points. The evaluation of the monitors was the best (9,56, SD 0,93) and the worst was the time dedicated to the laboratory (7,4 points, SD 2,22). The students improved their knowledge in 7 questions of the 11 questions asked as an avergae. Being the knowledge about the times of insufflation where more improved. In the remaining 4 the students responded worse, being the knowledge on CPR material the one that worsened (24 erroneous answers).

Conclusions: Students' satisfaction and the knowledge acquired about CPR with the laboratories was remarkable. It is necessary to reduce the ratio of students per laboratory to improve satisfaction.
\end{abstract}

Keywords: Cardiopulmonary resuscitation; Pediatrics; Clinical simulation, university teaching, educational innovation. 


\section{Introduction}

The program of Educational Innovation in basic and advanced cardiopulmonary resuscitation in pediatrics and neonatology is included within the subject "Nursing in Child and Adolescent Health" (NCAH), taught in the 2nd year of the degree in Nursing of the Faculty of Nursing and Podiatry (FNP) of the University of Valencia. It is part of a project of Educational Innovation and Improvement of teaching quality, the Service of Lifelong Learning and Educational Innovation (SLLEI) of the University of Valencia and belongs to the program "Renewal of teaching methodologies" which seeks to experience scenarios where projects are included of innovation of a general nature, aimed at discovering new methodological instruments and new techniques to improve teaching-learning processes (Uv.es, 2017).

In this educational program, taught in the academic year 2016/2017, several clinical situations of the critical pediatric and neonatal context were designed, in which the students of the NCAH had to face different scenarios in which to dynamically implement the knowledge, skills and attitudes acquired throughout the academic year. This type of training is based on the training of students based on competence and for this we must incorporate new methodologies and introduce practices in teaching, thus achieving improvements in the teaching process -learning (Calveras, 2003).

Students must be exposed to clinical situations where they can discuss about possible solutions, to later make decisions. For this reason, the incorporation of clinical simulation in nursing teaching is important, since the professional future will face complex and changing dilemmas to which it must be able to cope (Figueroa, 1999).

The clinical health simulation is defined as a controlled situation of reality and, in the case of nursing, it is considered the experience that mimics a realistic environment and that requires individuals or simulators to demonstrate, practice or learn procedures or techniques, as well as taking of decisions and develop critical thinking in order to provide quality care and insurance for the patient (Guimond, Sole, \& Salas, 2011; Urra, Sandoval, \& Irribarren, 2017; Jeffries, 2005).

For Gaba, considered in some manuals as the "father of simulation", simulation is a teaching technique and not a technology, which should be used to replace or amplify real experiences, in guided experiences that replicate substantial aspects of the real world, of a Interactive way (Casal, 2016; Gaba, 2004).

This type of teaching methodology is important for training in the proper handling of an emergency situation, since is very difficult to train and evaluate during the actual emergency. When a critical situation occurs, there is no time to stop and think about what the next step will be, for this reason it is essential to control the protocol of action, to know 
what actions have to be performed. And the only way to practice an emergency situation (in this case cardiopulmonary resuscitation) without endangering the patient's life is through a simulated environment (De la Horra, 2010).

\section{Project}

Along the years, 3rd and 4th degree students have attended other subjects where they have continued to carry out activities related to CPR in adults, but not in children or neonates. For this reason, it is essential that these students have direct contact with the practices and instruments of the child and neonate mannequins to consolidate the knowledge they acquired in the 2 nd year.

It was decided to design this teaching program in collaboration with other subjects (Medical-surgical Nursing, Practicum III, IV and Emergencies and Extra-Hospital Emergencies), in order to improve knowledge and skills of the framework of urgent assistance in the serious infant and neonate that needs to receive basic and advanced life support.

The expected results are specified in a special way in the acquisition not only of a technical training, but also teamwork with clear objectives, the handling of appropriate and specific material, in an environment of difficulty close to reality and in a environmental simulation with the coordination of the professors of the different subjects and health professionals.

The 3rd and 4th year students who participated in educational innovation project received prior training, in which they had to respond to the clinical cases raised (cases that they subsequently implemented as monitors). And in addition, it is a way to consolidate the knowledge already acquired in the course of the subject by being the ones who teach other classmates.

\subsection{Aims}

The aims of the project were:

- Increase the ability and autonomy of students in an emergency situation such as CPR in the pediatric population.

- Evaluate the knowledge about pediatric CPR and teamwork after the CPR practice of all the students who were in 2 nd year.

- Strengthen the knowledge on CPR of students of 3rd and 4th years who participated as monitors. 
- Evaluate the knowledge about pediatric CPR before and after the educational intervention, as well as the satisfaction of the students regarding this teaching methodology.

\subsection{Methodology}

In order to develop the project, $17 \mathrm{CPR}$ practical lessons of 2 hours duration were carried out, in which 225 students participated in the 2nd year of the studies in the subject of Nursing in Child and Adolescent Health.

Six students of 3rd and 4th years of nursing studies and 13 nurses participated as monitors of the simulation (12 nursing degree teachers from different subjects) participated on the simulation. Previous and acquired knowledges were evaluated by means of two tests (pretest and post-test). The satisfaction of the students regarding the simulation was also evaluated through a questionnaire passed at the end of the simulation.

The questionnaire to evaluate satisfaction was anonymous. It was intended to know the opinion about the development of the training and thus identify elements of improvement.

The questionnaire consisted of 20 items, scored from 0-10 according to the degree of satisfaction or agreement that the students had in this regard; 0 being the "lowest level of satisfaction or totally disagree" and 10 the "highest satisfaction or totally agree ".

In this way, different aspects related to the laboratory were evaluated: laboratory utility, methodology, organization and resources, teachers and general evaluation.

On the other hand, knowledge's evaluation was carried out with two tests: one before starting the laboratory (pre-test) and the other at the end (post-test). Both questionnaires were anonymous, and contained 11 questions. The format was multiple choice questions, only one being correct. The only variation between the post-test and pre-test was the order of the answer.

Prior to the practical lessons, where the clinical simulations were developed, a theoretical class was given to the students of 2nd year, where the recommendations of the 2015 European Resuscitation Council on basic and advance pediatric and neonatal CPR were explained.

Subsequently, between May 2 and 15 of 2017, the simulation laboratories were carried out. Approximately 15 students of 2nd-year participated in each laboratory. In each of them 3 clinical cases were carried out in which the scenario created for this purpose was that of a subway accident where there were multiple victims.

Each case was supervised by a member of the innovation group and the distribution of them was done in the following way: 
1. Advanced CPR on a 2-year-old pediatric patient: NCAH teacher.

2. Instrumented $\mathrm{CPR}$ in premature $\mathrm{RN}$ : student of $3 \mathrm{rd}$ or 4 th year attached to innovation.

3. Basic CPR in a 2-month-old infant: 3rd or 4th year student assigned to innovation.

4. Evaluation of the tutors: FNP professor assigned to innovation.

The tutor in each case was in charge of evaluating the intervention of the students while one of the collaborating teachers was responsible for assessing (without participating directly) the performance of students during the simulation. After the simulation this teacher directed the debriefing, allowing to evaluate the learning results.

The distribution of time and functions was carried out in the following way:

Table 1. Distribution of time and functions in the laboratory.

\begin{tabular}{cccc}
\hline Previous & First part & Second part \\
\hline $\begin{array}{c}\text { Instructors (students and } \\
\text { professors) }\end{array}$ & Deliver pre-test & $\begin{array}{c}\text { 10 minutes } \\
\text { Tutorize assigned } \\
\text { clinical case }\end{array}$ & $\begin{array}{c}\text { Collaborate in the } \\
\text { evaluation of the } \\
\text { students }\end{array}$ \\
Evaluating teachers & Fill in check-list & $\begin{array}{c}\text { Lead the evaluation of } \\
\text { the laboratory } \\
\text { (debriefing) }\end{array}$ \\
Students NCAH & Fill pre-test & $\begin{array}{c}\text { Realisation of } \\
\text { clinical cases }\end{array}$ & $\begin{array}{c}\text { Active participation. } \\
\text { Fill in post-test and } \\
\text { satisfaction survey }\end{array}$ \\
\end{tabular}

Source: Own preparation.

Each group (of 5 students) had 20 minutes per case. After the 20 minutes, each group had to give or receive the change of information about the case to follow where the other group had left it. Each group performed 3 cases in a total of 60 minutes. This meant that the practical laboratory lasted approximately 60 minutes, leaving the remaining time (less than 60 minutes) to perform the debriefing, as reflected in "table 1". 


\subsection{Results}

Figure 1 shows the average score of each of the items of the satisfaction questionnaire:

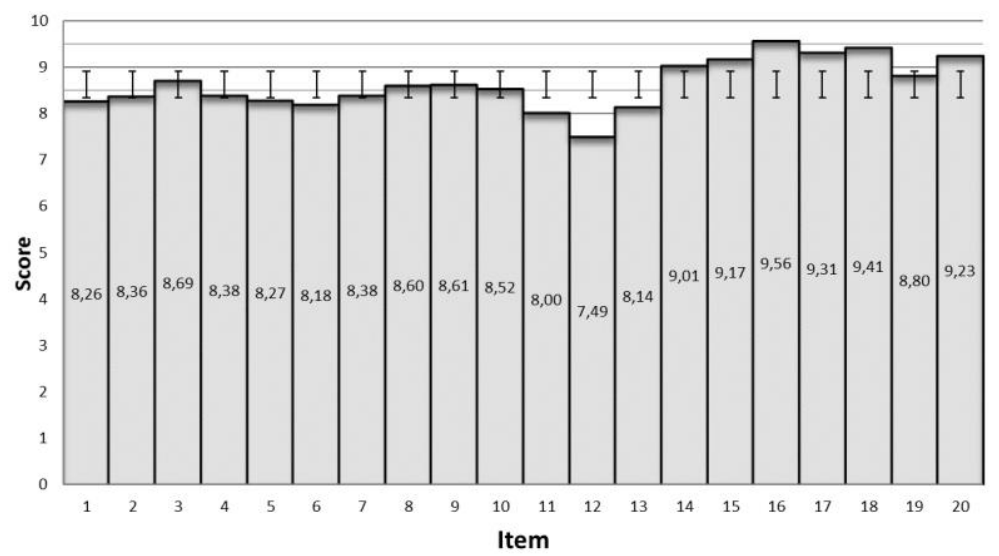

Figure 1. Satisfaction survey results. Source: Own preparation.

The average satisfaction of the students was 8.62 (SD 0.53) out of 10 points. Being the item "proficiency level of teachers" the best valued (9.56). In addition, the students rated the teachers had favored participation (9.41), had maintained interest in the case (9.31) and that they would recommend this laboratory on CPR to other students (9.23). These results showed that the selection of the teaching staff and the training of the 3rd and 4th year students was adequate to the objectives set.

However there are factors that, although it is necessary to improve, are difficult to control. The time it takes a laboratory is 2 hours and it is necessary to assemble the entire laboratory before starting, so that the effective laboratory time is 90 real minutes. This factor was the worst rated of all (7.49).

As for the results of the pre-test and the post-test, the following graph shows in a comparative way the percentage of correct answers, errors and answers in blank in each of the questions. 


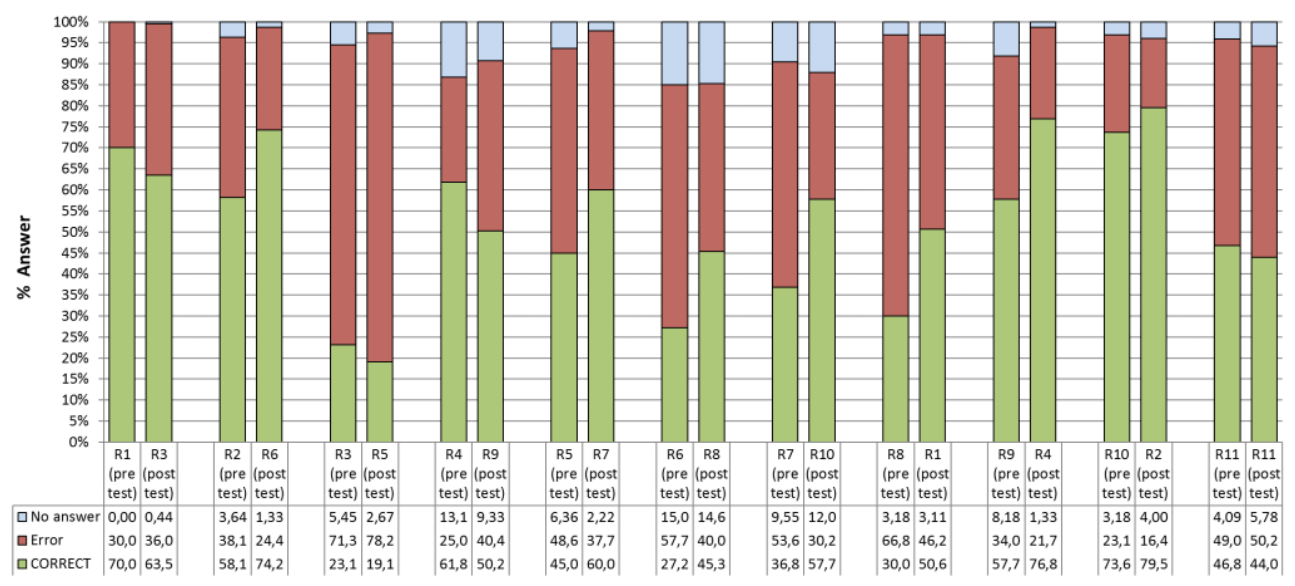

Figure 2. Pretest results vs posttest results. Source: Own preparation.

Regarding the acquired knowledge, the students improved their knowledge in 7 of the 11 questions of the questionnaire.

The question that was answered most correctly in both questionnaires $(73.6 \%$ were correct in the pre-test and $79.6 \%$ in the post-test), was the one about how to act in a foreign body choking situation in a one-month-old infant. The question that showed a greater increase of correct answers (in the post-test, $20.7 \%$ of correct answers were increased) was the one about the time a mouth-to-mouth ventilation lasts. Both results may be due to the fact that the training focused on the performance in front of the airway. The students had to perform both techniques in the three clinical cases what reinforced the acquired knowledge.

On the other hand, the question with the most errors $(71.40 \%$ failed in the pre-test and $78.22 \%$ in the post-test) was the one about chest compression in children of 5 years. While the question, which worsened in comparison with the first survey, was related to the material needed to perform an instrumentalized CPR (25\% in the pre-test and $40.40 \%$ in the post-test.) These results, in turn, they may be due to the fact that in only one of the cases an instrumentalized CPR was performed and that no clinical simulation case exceeded 3 years of age.

The debriefing directed by the collaborating teachers was not recorded in this simulation, this being an important limitation of the study. For the next edition, in the 2017/2018 academic year, a registration process has been designed by means of a video camera with the collaboration of the Department of Audiovisual Communication and Advertising of the University of Valencia. The main ideas of debriefing witnessed by members of the research team and teacher emphasized the impotence felt by the students because they do not know how to act. They reported, in the totality of the simulations, that their biggest competence problem was the lack of knowledge about the preparation of medication and the distribution 
of roles in the simulation team. For future research on clinical simulations, we propose that interventions in debriefing should be recorded with a video camera and voice recorder.

\section{References}

Calveras, A. C. (2003). Nuevos planteamientos didácticos: ¿Al innovar en docencia, mejoramos el aprendizaje?, 18-21.

Casal Angulo, M. (2016). La simulación como metodología para el aprendizaje de habilidades no técnicas en Enfermería. Universidad de Valencia.

De la Horra Gutiérrez, I. (2010). La simulación clínica como herramienta de evaluación de competencias en la formación enfermera. Reduca. Universidad Complutense de Madrid.

Durá Ros, M. J. (2013). La simulación clínica como metodología de aprendizaje y adquisición de competencias en Enfermería. Universidad Complutense de Madrid.

Figueroa, A. A. (1999). La innovación en la educación superior en enfermería y los aportes del diseño de instrucción. Revista Latino-Americana de Enfermagem, 7(2), 5-13. http://doi.org/10.1590/S0104-11691999000200002

Gaba, D. (2004). The future vision of simulation in health care. Quality and Safety in Health Care, 13(suppl_1), i2-i10. http://doi.org/10.1136/qshc.2004.009878

Guimond, M., Sole, M., \& Salas, E. (2011). Getting ready for simulation- based training: A checklist for nurse educators. Nurs Educ Perspect, 32(3), 179-185.

Jeffries, P. R. (2005). A Framework for Designing, Implementing, and Evaluating Simulations Used as Teaching Strategies in Nursing. Nursing Education Perspectives, 26(2), 96-103.

Urra Medina, E., Sandoval Barrientos, S., \& Irribarren Navarro, F. (2017). El desafío y futuro de la simulación como estrategia de enseñanza en enfermería. Investigación En Educación Médica, 6(22), 119-125. http://doi.org/10.1016/j.riem.2017.01.147

Uv.es. (2017). Convocatoria de proyectos de innovación educativa y mejora de la calidad docente, curso 2017/18. Retrieved January 24, 2018, from https://www.uv.es/ 